\title{
VDTA Based Electronically Tunable Purely Active Simulator Circuit for Realizing Floating Resistance
}

\author{
Mayank Srivastava*,1 and Dinesh Prasad ${ }^{2}$ \\ ${ }^{I}$ Deptt. of Electronics and Communication Engineering, ASET, Amity University Uttar Prasdesh, Sector 125, Noida \\ (U.P.), India \\ ${ }^{2}$ Deptt. of Electronics and Communication Engineering, FET, Jamia Millia Islamia, New Delhi, India
}

Received 18 January 2015; Accepted 13 April 2015

\begin{abstract}
This paper proposes a new active synthetic floating resistor circuit employing three voltage differencing transconductance amplifiers (VDTAs). The proposed configuration enjoys following advantageous features; (a) purely active realization (b) electronically tunable resistance (c) no external component matching constraint(s) (d) good nonideal behavior and (e) low sensitivity values. The workability of proposed resistor simulator has been verified by an application example of voltage mode low-pass filter. To validate the theoretical analysis SPICE simulations with TSMC $0.18 \mu \mathrm{m}$ CMOS process parameters have been performed.
\end{abstract}

Keywords: VDTA, Synthetic resistor, floating resistor, electronic control, purely active simulation circuit

\section{Introduction}

Active simulation of floating passive elements (resistors/capacitors/inductors) is a fascinating research area for analog circuit designers and researchers. Several floating passive component simulators have been proposed in [1][16] and reference cited therein. The floating resistor is an integral part of analog circuits but the use of resistor in floating state is not advisable from the viewpoint of monolithic integration as a floating resistor need more chip area than a grounded resistor and also it is very difficult to design such a resistor with exact resistance value. Moreover, the resistance is fixed and cannot be changed as per requirement. So, the active simulation of floating resistors has become a popular research area in which a floating resistor is realized either by using active element(s) alone or by using active element(s) along with grounded resistors(s.).There are several synthetic floating resistor configurations available in literature but electronic tunability is available with very few configurations [11-16]. The negative floating resistor proposed in [11] was purely active realization and need four current controlled second generation current conveyors (CCCII). The configuration proposed in [12] employs one second generation current conveyor (CCII) and one operational transconductance amplifier (OTA) along with two grounded resistors. A current backward transconductance amplifier (CBTA) based floating resistance simulator circuit employing two CBTA and three grounded resistors has been presented in [13]. An improved CBTA based floating resister simulation circuit has been proposed in [14] which employs single CBTA along with two grounded resistors but this circuit needs current/voltage gain matching constraints. Positive/negative floating resistance simulation circuits employing two/three current follower transconductance amplifiers (CFTA) have been proposed in [15] but in both the cases matching condition of transconductances are required. The configuration proposed in [16] employs two DVCC and three grounded resistors but in non ideal conditions it does not simulate lossless floating resistor.

Therefore, the aim of this paper is to propose new electronically tunable synthetic floating resistor configuration employing three VDTAs with no requirement of any external grounded resistor. The proposed circuit exhibits low sensitivity values and excellent non- ideal behavior.

\section{Proposed Configuration}

The voltage differencing transconductance amplifier (VDTA) is one of the active elements which have been introduced in [17]. It provides currents and voltages at different terminals with electronically tunable transconductance gains. Therefore, VDTA block is very suitable for synthesis and design of active circuits with electronic tunability feature. Fig.1 shows the symbolic representation of VDTA, where $\mathrm{P}$ and $\mathrm{N}$ are input ports, $\mathrm{z}$ is auxiliary port and $\mathrm{X}+$ and $\mathrm{X}$ - are output ports with all ports at high impedance level. The CMOS implementation of VDTA [18] has been shown in Fig. 2.

* E-mail address: mayank2780@gmail.com, ISSN: 1791-2377 @ 2015 Kavala Institute of Technology. All rights reserved. 


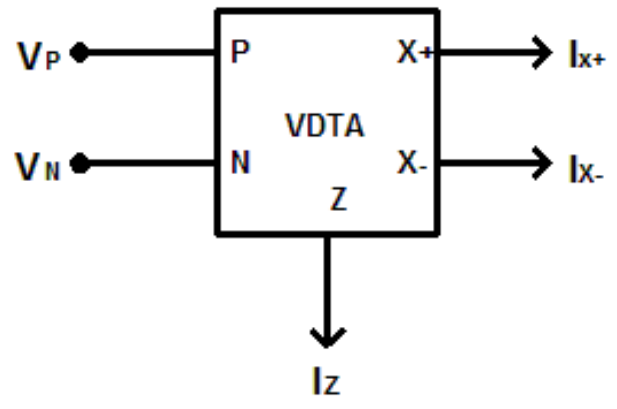

Fig. 1. VDTA symbolic representation

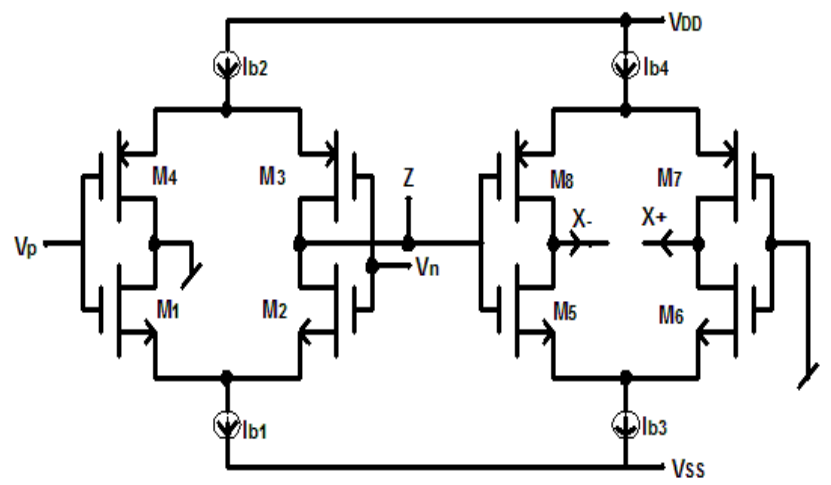

Fig. 2. CMOS implementation of VDTA [18]

The port relations of ideal VDTA shown in Fig. 1 can be characterized by following hybrid matrix ;

$$
\left[\begin{array}{c}
I_{Z} \\
I_{X^{+}} \\
I_{X^{-}}
\end{array}\right]=\left[\begin{array}{ccc}
g_{m_{1}} & -g_{m_{1}} & 0 \\
0 & 0 & g_{m_{2}} \\
0 & 0 & -g_{m_{2}}
\end{array}\right]\left[\begin{array}{c}
V_{P} \\
V_{N} \\
V_{Z}
\end{array}\right]
$$

The trans-conductance gains $\mathrm{g}_{\mathrm{m} 1}$ and $\mathrm{g}_{\mathrm{m} 2}$ of CMOS VDTA shown in Fig. 2 are given as

$$
\begin{aligned}
& g_{m_{1}}=\frac{g_{3}+g_{4}}{2} \\
& g_{m_{2}}=\frac{g_{5}+g_{8}}{2} \text { or } g_{m_{2}}=\frac{g_{6}+g_{7}}{2}
\end{aligned}
$$

Where, $g_{n}$ is the transconductance of $n^{\text {th }}$ MOS transistor given as

$$
g_{n}=\sqrt{I_{B_{n}} \mu_{n} C_{O X}\left(\frac{W}{L}\right)_{n}}
$$

where, $\mu_{\mathrm{n}}$ is carrier mobility, $\mathrm{C}_{\mathrm{OX}}$ is capacitance of gateoxide layer per unit area, W is MOS transistors's effective channel width, $\mathrm{L}$ is effective channel length and $\mathrm{I}_{\mathrm{Bn}}$ is bias current of $\mathrm{n}^{\text {th }}$ transistor.

VDTA find several applications in designing of analog filters [19-21], oscillators [22] and inductor simulators [23] but there is no application in simulation of floating resisters has been reported so far. So, this paper is an effort to fill this void
The proposed purely active floating resister simulator is shown in Fig. 3.

The Routine circuit analysis of configuration shown in Fig. 3 yields short circuit admittance matrix as

$\left[\begin{array}{c}I_{\text {in }} \\ I_{\text {out }}\end{array}\right]=\frac{g_{m_{A}} g_{m_{B}}}{g_{m_{3}}}\left[\begin{array}{ll}+1 & -1 \\ -1 & +1\end{array}\right]\left[\begin{array}{l}V_{\text {in }} \\ V_{\text {out }}\end{array}\right]$

Which simulate a floating resistor with resistance value:

$$
R_{e q}=\frac{g_{m_{3}}}{g_{m_{A}} g_{m_{B}}}
$$

for $\mathrm{g}_{\mathrm{m} 2}=\mathrm{g}_{\mathrm{m} 6}=\mathrm{g}_{\mathrm{mA}}$ and $\mathrm{g}_{\mathrm{m} 1}=\mathrm{g}_{\mathrm{m} 5}=\mathrm{g}_{\mathrm{mB}}$

Where $\left(g_{m 1}, g_{m 2}\right),\left(g_{m 3}, g_{m 4}\right)$ and $\left(g_{m 5}, g_{m 6}\right)$ are the transconductances of VDTA-1, VDTA-2 and VDTA-3 respectively. These transconductance matching conditions can be meet easily just by equating the bias currents of VDTAs.

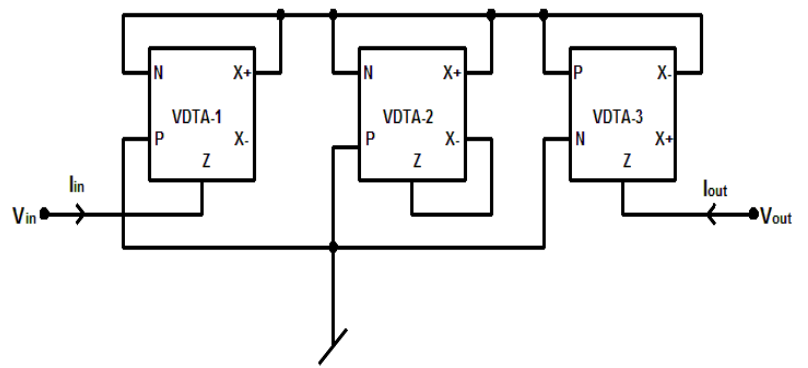

Fig. 3. Proposed purely active floating resistor simulator

One can observe from Eq. 6 that the resistance of proposed synthetic resistor can be controlled electronically by varying transconductances $\mathrm{g}_{\mathrm{m} 1}, \mathrm{~g}_{\mathrm{m} 2}, \mathrm{~g}_{\mathrm{m} 3}, \mathrm{~g}_{\mathrm{m} 5}$ or $\mathrm{g}_{\mathrm{m} 6}$. It is important to note that the presented circuit can also simulate negative floating resistor (-R) by appropriate interchanging of $\mathrm{p}$ and $\mathrm{n}$ and/or $\mathrm{x}+$ and $\mathrm{x}$ - ports of VDTAs. Such negative resistor simulator can be used for parasitic cancellation purpose.

\section{Non-Ideal and Sensitivity Analysis}

In the non ideal case, the VDTA can be characterized by the following equations;

$I_{Z}=\beta_{Z} g_{m_{1}}\left(V_{P}-V_{N}\right)$

$I_{X+}=\beta_{x+} g_{m_{2}} V_{Z}$

$I_{X-}=-\beta_{x-} g_{m_{2}} V$

where $\beta_{Z}, \beta_{X+}$ and $\beta_{X \text { - }}$ are non ideal transconductance gain errors.

To check the behaviour of presented configuration under non ideal conditions, it is revisited considering the non ideal model of VDTA described by Eq. 7-9. The short Circuit admittance matrixes and floating resistances values of proposed simulator under the influence of VDTAs non idealities can be re-expressed as 
$\left[\begin{array}{c}I_{\text {in }} \\ I_{\text {out }}\end{array}\right]=\frac{g_{m_{A}} g_{m_{B}} \beta_{x_{2}-} \beta_{A} \beta_{B}}{g_{m_{3}} \beta_{x_{2}+} \beta_{z_{2}}}\left[\begin{array}{ll}+1 & -1 \\ -1 & +1\end{array}\right]\left[\begin{array}{c}V_{\text {in }} \\ V_{\text {out }}\end{array}\right]$

and

$$
R_{e q}=\frac{g_{m_{3}} \beta_{x_{2}+} \beta_{z_{2}}}{g_{m_{A}} g_{m_{B}} \beta_{x_{2}-} \beta_{A} \beta_{B}}
$$

For $\mathrm{g}_{\mathrm{m} 2}=\mathrm{g}_{\mathrm{m} 6}=\mathrm{g}_{\mathrm{mA}}, \mathrm{g}_{\mathrm{m} 1}=\mathrm{g}_{\mathrm{m} 5}=\mathrm{g}_{\mathrm{mB}}, \beta_{\mathrm{x} 1+}=\beta_{\mathrm{x} 3-}=\beta_{\mathrm{A}}$ and $\beta_{\mathrm{Z} 1}=\beta_{\mathrm{Z} 3}=\beta_{\mathrm{B}}$.

where $\left(\beta_{Z 1}, \beta_{X 1+}, \beta_{X 1-}\right),\left(\beta_{Z 2}, \beta_{X 2+}, \beta_{X 2-}\right)$ and $\left(\beta_{Z 3}, \beta_{X 3+}, \beta_{X 3-}\right)$ are the transconductance gain errors of VDTA-1, VDTA-2 and VDTA-3 respectively.

It is clear from Eq. 11 that even under the non ideal conditions the proposed configuration simulates the lossless floating resistor without any lossy term.

The sensitivity figures of resistance of simulated floating resistor with respect to transconductance gains/ gain errors are found as;

$S_{g_{m}}^{R_{e q}}=S_{g_{m_{2}}}^{R_{e q}}=S_{g_{m 5}}^{R_{e q}}=S_{g_{m_{6}}}^{R_{e q}}=-1, S_{g_{m 3}}^{R_{e q}}=1$,

$S_{\beta_{x 2-}}^{R_{e q}}=S_{\beta_{x 1+}}^{R_{e q}}=S_{\beta_{x 3-}}^{R_{e q}}=S_{\beta_{z 1}}^{R_{e q}}=S_{\beta_{z 3}}^{R_{e q}}=-1, S_{g_{m 4}}^{R_{e q}}=0$,

$S_{\beta_{x 2+}}^{R_{e q}}=S_{\beta_{z 2}}^{R_{e q}}=1$

So, all the sensitivity figures are low and not more than unity in magnitude.

\section{Effects of Parasitics}

At high frequency, the terminal parasitic of VDTA comes into the picture and effect the performance of a VDTA based circuit. A conventional VDTA along with its port parasitic has been shown in Fig. 4.

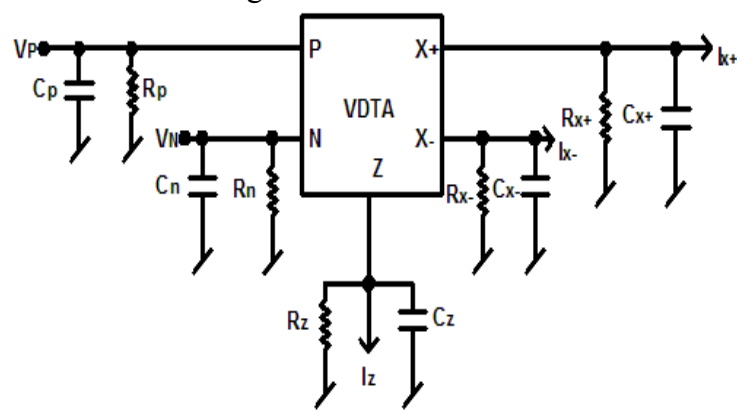

Fig. 4. Conventional VDTA with port parasitics

§To study the effects of terminal parasitic of VDTAs on proposed resistance simulator configuration, this configuration was examined including port parasitic of VDTA. Fig. 5 shows the proposed resistance simulator with port parasitic of VDTA-1, VDTA-2 and VDTA-3.

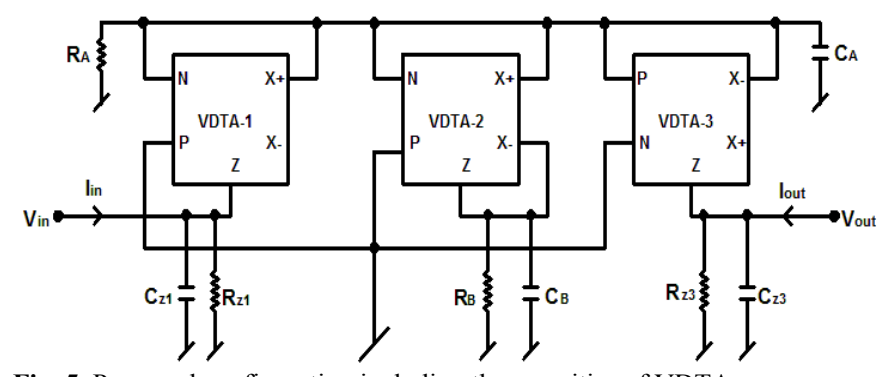

Fig. 5. Proposed configuration including the parasitics of VDTAs Where

$$
\begin{aligned}
& R_{A}=\frac{1}{\frac{1}{R_{n_{1}}}+\frac{1}{R_{X_{1}+}}+\frac{1}{R_{n_{2}}}+\frac{1}{R_{X_{2}+}}+\frac{1}{R_{p_{1}}}+\frac{1}{R_{X_{3}-}}} \\
& C_{A}=C_{n_{1}}+C_{n_{2}}+C_{p_{3}}+C_{x_{1}+}+C_{x_{2}+}+C_{x_{3}-} \\
& R_{B}=\frac{1}{\frac{1}{R_{z_{2}}}+\frac{1}{R_{X_{2}-}}}
\end{aligned}
$$

and

$C_{B}=C_{z_{2}}+C_{x_{2}-}$

As the proposed configuration does not have any external passive component, so effects of parasitics cannot be alleviated. Hence, port parasitics of VDTAs will limit the high frequency behaviour of proposed configuration. So, the maximum usable frequency can be found as:

$\omega_{0_{\max }}\left\langle\left\langle\min \left\{\frac{\left(\frac{1}{R_{n_{1}}}+\frac{1}{R_{n_{2}}}+\frac{1}{R_{p_{3}}}+\frac{1}{R_{x_{1}+}}+\frac{1}{R_{x_{2}+}}+\frac{1}{R_{x_{1}-}}\right)}{\left(C_{n_{1}}+C_{n_{2}}+C_{p_{3}}+C_{x_{1}+}+C_{x_{2}+}+C_{x_{3}-}\right)}, \frac{1}{R_{z_{1}} C_{z_{1}}}, \frac{1}{R_{z_{3}} C_{z_{3}}}, \frac{\left(\frac{1}{R_{z_{2}}}+\frac{1}{R_{x_{2}-}}\right)}{\left(C_{z_{2}}+C_{x_{2}}-\right.}\right)\right\}\right.$

\section{Application Examples}

The workability of proposed circuit is also verified by lowpass filter design example. The passive RC low-pass filter employing a floating resistor and a grounded capacitor has been shown in Fig. 6(a) and active realization of this lowpass filter using proposed resistor simulator is shown in Fig. 6(b).

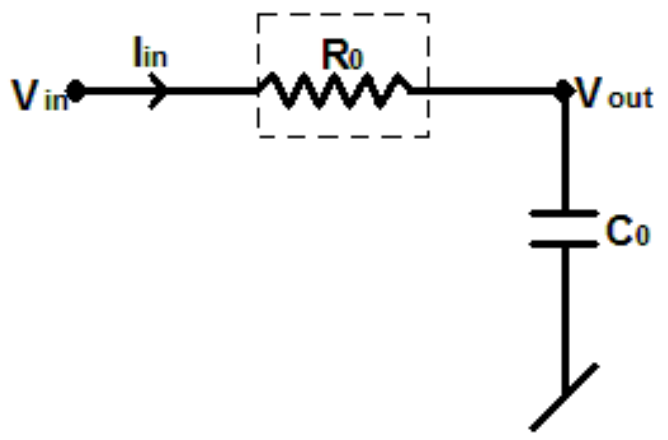

(a) 


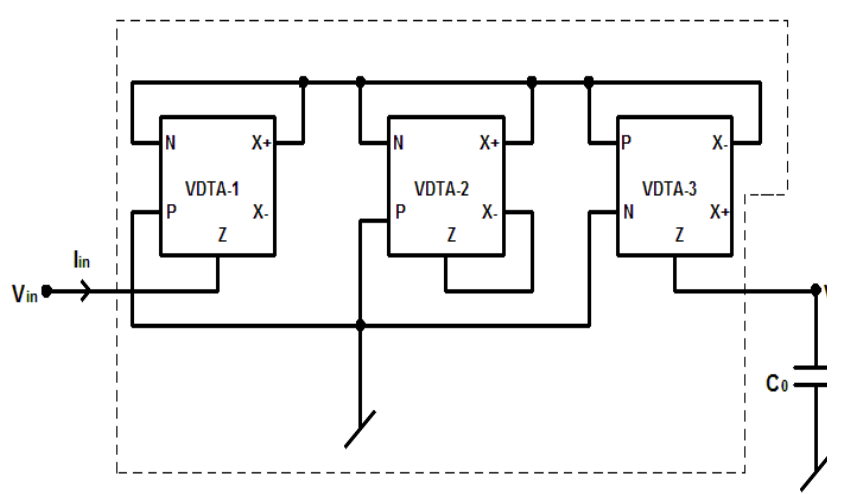

(b)

Fig. 6. Voltage-mode low-pass filter (a) Pasive realization (b) active realiazation employing proposed floating resistance simulator

The voltage mode transfer function obtained from Fig. $6(b)$ is given by Eq.18, which is low-pass transfer function.

$$
\frac{V_{\text {out }}(s)}{V_{\text {in }}(s)}=\frac{1}{1+\frac{s C_{0} g_{m_{3}}}{g_{m_{A}} g_{m_{B}}}}
$$

\section{Simulation Results}

The circuit illustrated in Fig. 3 is tested by SPICE simulations with TSMC $0.18 \mu \mathrm{m}$ process parameter model. The simulations were performed employing CMOS VDTA (shown in Fig. 2) with supply voltages \pm 0.9 VDC and bias currents $\mathrm{I}_{\mathrm{b} 1}=\mathrm{I}_{\mathrm{b} 2}=\mathrm{I}_{\mathrm{b} 3}=\mathrm{I}_{\mathrm{b} 4}=\mathrm{I}_{\mathrm{b} 5}=\mathrm{I}_{\mathrm{b} 6}=\mathrm{I}_{\mathrm{b} 7}=\mathrm{I}_{\mathrm{b} 8}=\mathrm{I}_{\mathrm{b} 9}=\mathrm{I}_{\mathrm{b} 10}=$ $\mathrm{I}_{\mathrm{b} 11}=\mathrm{I}_{\mathrm{b} 12}=\mathrm{I}_{\mathrm{b}}=150 \mu \mathrm{A}$, where $\mathrm{I}_{\mathrm{b} 1}, \mathrm{I}_{\mathrm{b} 2}, \mathrm{I}_{\mathrm{b} 3}$ and $\mathrm{I}_{\mathrm{b} 4}$ are the bias currents of VDTA1, $\mathrm{I}_{\mathrm{b} 5}, \mathrm{I}_{\mathrm{b} 6}, \mathrm{I}_{\mathrm{b} 7}$ and $\mathrm{I}_{\mathrm{b} 8}$ are the bias currents of VDTA2 and $\mathrm{I}_{\mathrm{b} 9}, \mathrm{I}_{\mathrm{b} 10}, \mathrm{I}_{11}$ and $\mathrm{I}_{\mathrm{b} 12}$ are the bias currents of VDTA-3. The magnitude and phase response of impedance of proposed simulator have been shown in Fig.8. It is seen from Fig. 8(a) that simulated magnitude response is approximately same as ideal magnitude response up to $286 \mathrm{MHz}$ frequency (simulated resistance value is found $1.566 \mathrm{k} \Omega$ while ideal value is $1.571 \mathrm{k} \Omega$. The phase response plots, as shown in Fig. 8(b) clearly indicates that simulated phase response matches the ideal phase response up to 30 $\mathrm{MHz}$ frequency. The deviation of simulated responses from ideal responses at high frequencies is due to presence of VDTA parasitics.

To demonstrate the electronic control of proposed configuration, simulations have been performed for different set of bias currents. Fig. 10 illustrated the magnitude responses for $\mathrm{I}_{\mathrm{b}}=130 \mu \mathrm{A}$ and $110 \mu \mathrm{A}$. The simulated floating resistance values for $\mathrm{I}_{\mathrm{b}}=130 \mu \mathrm{A}$ and $110 \mu \mathrm{A}$ were found $1.667 \mathrm{k} \Omega$ and $1.830 \mathrm{k} \Omega$ while the ideal values were calculated as $1.689,1.836 \mathrm{k} \Omega$ Hence the deviation between simulated values and ideal values is not more than $1.5 \%$ in limited frequency region.

The low-pass filter shown in Fig. 6(b) is also simulated using CMOS VDTA with supply voltage of \pm 0.9 VDC. The value of capacitor $\mathrm{C}_{0}$ is chosen as $0.1 \mathrm{nF}$. The SPICE simulated frequency responses of this filters is shown in Fig. 9.

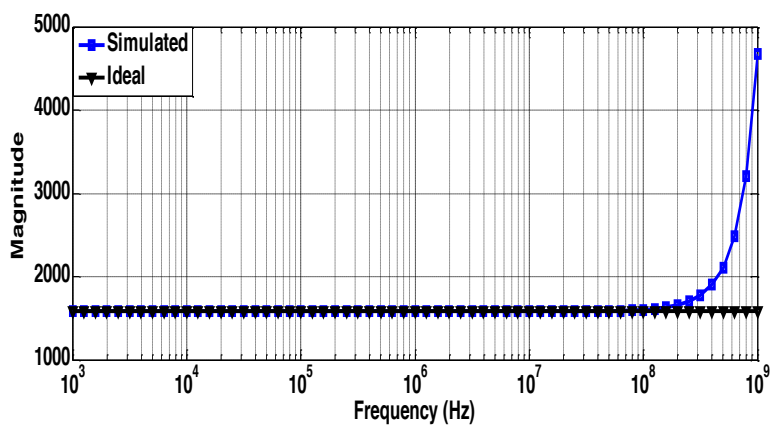

(a)

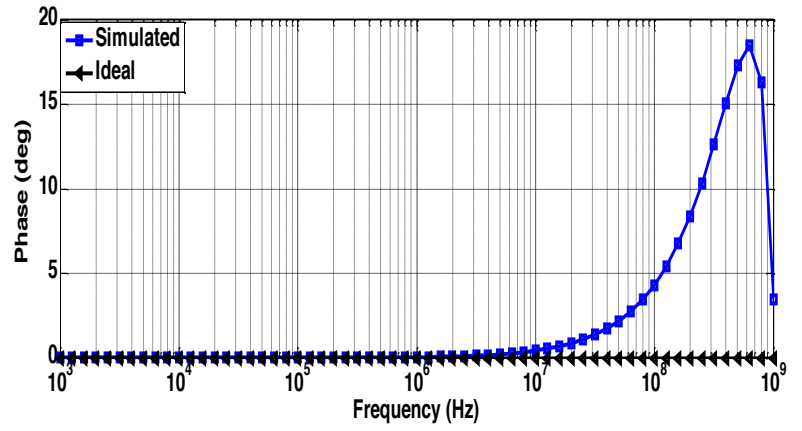

(b)

Fig. 7. Frequency reponses (a) Magnitude response (b) Phase response

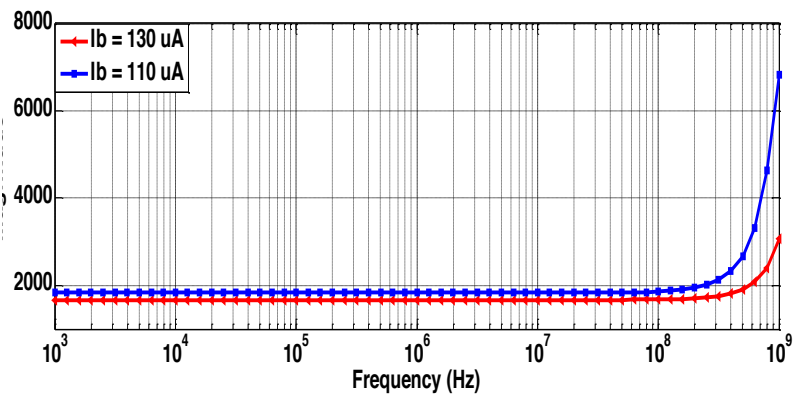

Fig. 8. Demonstration of elecronic control

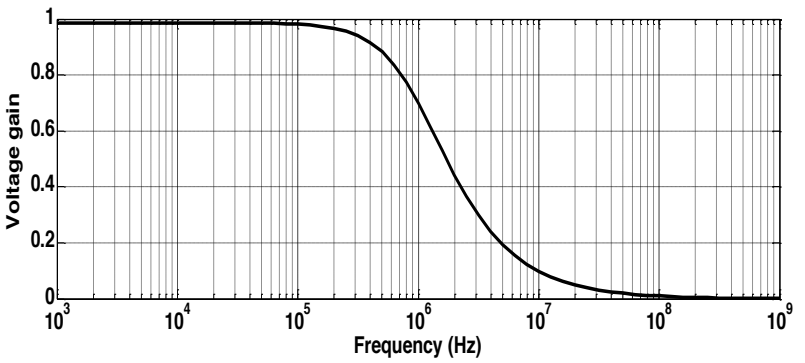

Fig. 9. Frequency response of low-pass filter shown in Fig. 6(b)

\section{Conclusion}

A new purely active floating resistor simulator employing three VDTAs has been presented. To the best knowledge of authors there is no purely active floating resistor simulator employing VDTA(s) has been available in literature. The proposed configuration enjoys electronically tunable resistance with low sensitivity indexes. The effects of nonidealities and parasitics of VDTA also have been investigated in proposed circuit. The application of proposed resistor simulator in designing of a low pass filter has been proposed and verified. The mathematical analysis has been verified by SPICE simulations with TSMC $0.18 \mu \mathrm{m}$ CMOS process parameters. 


\section{References}

1. S. Minaei, E. Yuce and O. Cicekoglu, A versatile active circuit for realizing floating inductance, capacitance, FDNR and admittance converter, Analog Integrated Circuits and Signal Processing, 47(2), pp.199-202 (2006)

2. K. Pal, New inductance and capacitor floatation schemes using current conveyors, Electronics Letters, 17(21), pp. 807-808 (1981).

3. P. V. Ananda Mohan, Floating capacitance simulation using current conveyors, Journal of Circuits Systems and Computers, 14(1), pp. 123-128 (2008).

4. P. Mongkolwai, T. Pukkalanun and W. Tangsrirat, Electronically tunable floating capacitance simulator with only VDTAs and a grounded capacitor, Proc. $4^{\text {th }}$ International Science, Social Science, Engineering and Energy Conference (2012).

5. A. Lahiri, DO-CCII based generalised impedance convertor simulates floating inductance, capacitance multiplier and FDNR, Australian Journal of Electrical \& Electronics Engineering, vol. 7(1) (2010).

6. M. A. Ibrahim, S. Minaei, E. Yuce, N. Herencsar, and J. Koton, Lossy/lossless floating/grounded inductance simulator using one DDCC, Radioengineering, 21(1), pp. 2-10 (2012).

7. E. Yuce, On the implementation of the floating simulators employing a single active device, International Journal of Electronics and Communications-AEU, 61(7), pp. 453-458 (2007).

8. S. Minaei, E. Yuce and O. Cicekoglu, A versatile active circuit for realizing floating inductance, capacitance, FDNR and admittance converter, Analog Integrated Circuits and Signal Processing, 47(2), pp.199-202 (2006).

9. E. Yuce, O. Cicekoglu and S. Minaei, CCII-Based Grounded to Floating Immittance Converter and a Floating Inductance Simulator, Analog Integrated Circuits and Signal Processing, 46(3), pp. 287-291 (2006).

10. R. A. Saad and A. M. Soliman, On the systematic synthesis of CCIIbased floating simulators, International Journal of Circuit Theory and Applications, 38(9), pp. 93-967 (2010).

11. E. Yuce, S. Minaei and O Cicekoglu, Resistorless floating immitance function simulators employing current controlled conveyors and a grounded capacitor, Electrical Engineering, 88(6), pp. 519-525 (2006).

12. M. Sagbas, U. E. Ayten, H. Sedef and M. Koksal, Floating immittance function simulator and its applications, Circuits Systems and Signal Processing, 28(1), pp. 55-63 (2009).

13. U. E. Ayten, M. Sagbas, N. Herencsar and J. Koton, Novel Floating General Element Simulators Using CBTA, Radioengineering, 21(1), pp. 11-19 (2012).

14. M. Sagbas Component reduced floating $\pm \mathrm{L}, \pm \mathrm{C}$ and $\pm \mathrm{R}$ simulators with grounded passive components, International Journal of Electronics and Communications-AEU, 65(10), pp.794-798 (2011).

15. Y. Li, A series of new circuits based on CFTAs, International Journal of Electronics and Communications-AEU, 66(7), pp. 587592 (2012).

16. E. Yuce, A novel floating simulation topology composed of only grounded passive components, International Journal of Electronics, 97(3), pp. 249-262 (2010).

17. D. Biolek, R. Senani, V. Biolkova and Z. Kolka, Active elements for analog signal processing; classification, review and new proposals, Radioengineering, 17(4), pp. 15-32 (2008).

18. A. Yesil, F. Kacar and H. Kuntman, New simple CMOS realization of voltage differencing transconductance amplifier and its RF filter application, Radioengineering, 20(3), pp. 632-637 (2011).

19. D.Prasad, D. R. Bhaskar and M. Srivastava, Universal CurrentMode Biquad Filter using a VDTA, Circuits and Systems, 4(1), pp. 32-36 (2013).

20. D. Prasad, D. R. Bhaskar and M. Srivastava, Universal voltagemode biquad filter using voltage differencing transconductance amplifier, Indian Journal of Pure and Applied Physics, 51(12), pp. 864-868 (2013).

21. D. Prasad, M. Srivastava and D. R. Bhaskar, Transadmittance - type universal current-mode biquad filter using voltage differencing transconductance amplifiers, International Scholarly Research Network, 4 pages (2014).

22. D. Prasad, M. Srivastava and D. R. Bhaskar, Electronically controllable fully uncoupled explicit current mode quadrature oscillator using VDTA and grounded capacitors, Circuits and Systems, 4(2), pp. 169-172(2013).
23. M. Srivastava, D. Prasad and D. R. Bhaskar, New Parallel R-L impedance using single VDTA \& its high pass filter applications, In Proc. of International Conference on Signal Processing and Integrated Networks-2014(SPIN-2014), Noida, pp. 535-537 (2014). 